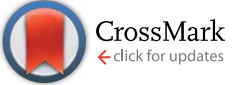

Cite this: J. Mater. Chem. A, 2016, 4, 791

Received 8th November 2015 Accepted 4th December 2015

DOI: $10.1039 / c 5 t a 09023 g$

www.rsc.org/MaterialsA

\section{A direct arylation approach towards efficient small molecule organic solar cells $\dagger$}

\author{
Julija Kudrjasova, ${ }^{\text {ab }}$ Jurgen Kesters, ${ }^{\text {ac }}$ Pieter Verstappen, ${ }^{a}$ Jeroen Brebels, ${ }^{a}$ \\ Tim Vangerven, ${ }^{c}$ Ilaria Cardinaletti, ${ }^{c}$ Jeroen Drijkoningen, ${ }^{c}$ Huguette Penxten, ${ }^{a}$ \\ Jean Manca, ${ }^{\mathrm{d}}$ Laurence Lutsen, $^{\mathrm{b}}$ Dirk Vanderzande ${ }^{\mathrm{ab}}$ and Wouter Maes ${ }^{\star a b}$
}

Three extended molecular chromophores, differing in their central acceptor moiety and specifically designed as electron donor components for small molecule organic solar cells, are synthesized via a two-fold $\mathrm{C}-\mathrm{H}$ arylation protocol. Upon removal of the side products inherent to the applied direct (hetero)arylation procedure, a record power conversion efficiency of $5.1 \%$ is achieved.

Solution-processed bulk heterojunction (BHJ) organic solar cells based on light harvesting and charge transporting conjugated polymers or analogous small molecules have attracted large attention from both academia and industry because of their appealing aesthetical (colour and transparency), mechanical (flexibility and light-weight) and cost features (large area production via simple printing processes). ${ }^{1}$ Small molecule organic solar cells (SMOSCs) have recently surpassed the $10 \%$ power conversion efficiency (PCE) barrier, thereby becoming a viable substitute for their polymeric counterparts. ${ }^{2}$ In comparison to semiconducting polymers, 'small' molecules display some peculiar beneficial features such as less batch-tobatch variability due to their well-defined structure, more reproducible synthetic protocols, easier purification and a more straightforward understanding of structure-performance relationships. ${ }^{3}$ Additionally, small molecules more readily allow the tuning of the optoelectronic (and other) material properties and they can exhibit fairly high charge carrier mobilities. State of the

${ }^{a}$ Design \& Synthesis of Organic Semiconductors (DSOS), Institute for Materials Research (IMO-IMOMEC), Hasselt University, Universitaire Campus, Agoralaan 1-Building D, B-3590 Diepenbeek, Belgium. E-mail: wouter.maes@uhasselt.be

${ }^{b} I M E C$, IMOMEC, Universitaire Campus, Wetenschapspark 1, B-3590 Diepenbeek, Belgium

${ }^{C}$ Materials Physics Division, Institute for Materials Research (IMO-IMOMEC), Hasselt University, Universitaire Campus, Wetenschapspark 1, B-3590 Diepenbeek, Belgium

${ }^{d} X-L a B$, Hasselt University, Universitaire Campus, Agoralaan 1-Building D, B-3590 Diepenbeek, Belgium

$\dagger$ Electronic supplementary information (ESI) available: General experimental methods, MALDI-TOF MS spectra, NMR spectra, UV-vis spectra (solution), cyclic voltammograms, solar cell optimization tables, EQE spectra, CPE structure, FTPS data and mobility data. See DOI: 10.1039/c5ta09023g art polymers and small molecule electron donor materials generally apply the alternating donor-acceptor (D-A) (or 'pushpull') strategy, allowing for a decrease of the HOMO-LUMO gap and a better overlap with the solar spectrum. $\cdot^{1-3}$ More advanced molecular scaffolds with D-A-D, A-D-A, D-A-A and even more extended architectures are acquiring increased attention to optimize photon collection and charge carrier transport. ${ }^{3}$ Thiazolo[5,4- $d]$ thiazole (TzTz) has emerged as an appealing electron withdrawing building block, showing particular advantages such as easy synthetic access, a planar and rigid structure with strong $\pi-\pi$ stacking tendency (promoting mobility) and oxidative stability. ${ }^{4}$ Due to these favourable features, TzTz-based polymers ${ }^{5}$ and small molecule ${ }^{6}$ materials have successfully been applied in organic photovoltaic devices, with record PCEs of 7.5 and $4.1 \%$, respectively. ${ }^{5 b, 6 d}$

Low bandgap organic semiconductors are generally synthesized through standard transition metal catalysed crosscoupling reactions to afford (het)aryl-(het)aryl connections, such as Suzuki and Stille reactions, requiring the preparation of organoboron or organotin precursors. Direct (hetero)arylation of activated $\mathrm{C}-\mathrm{H}$ moieties has emerged as a viable alternative, with specific benefits in terms of (atom) efficiency, sustainability and functional group compatibility, and it has been applied for SMOSC materials with reasonable success. ${ }^{7}$ In the previous work, we have demonstrated a facile direct arylation strategy towards diaryl-substituted 2,5-dithienyl-TzTz small molecules with varying electron affinities, particularly emphasizing on monosubstitution towards asymmetric push-pull structures. ${ }^{7 d}$ The first generation TzTz chromophores showed a relatively narrow absorption window and SMOSC efficiencies remained below $3 \%$. Prompted by these initial results, more complex structures were pursued, still avoiding traditional cross-coupling protocols. In the present contribution, we report on the combination of an asymmetric triphenylamine-monosubstituted 2,5-dithienyl-TzTz precursor (TPA-T-TzTz-T) with three different brominated central acceptor derivatives bithiazole (BiTz), quinoxaline (Qx) and isoindigo (II) (Scheme 1), varying the electron affinity, solubility and stacking features - 


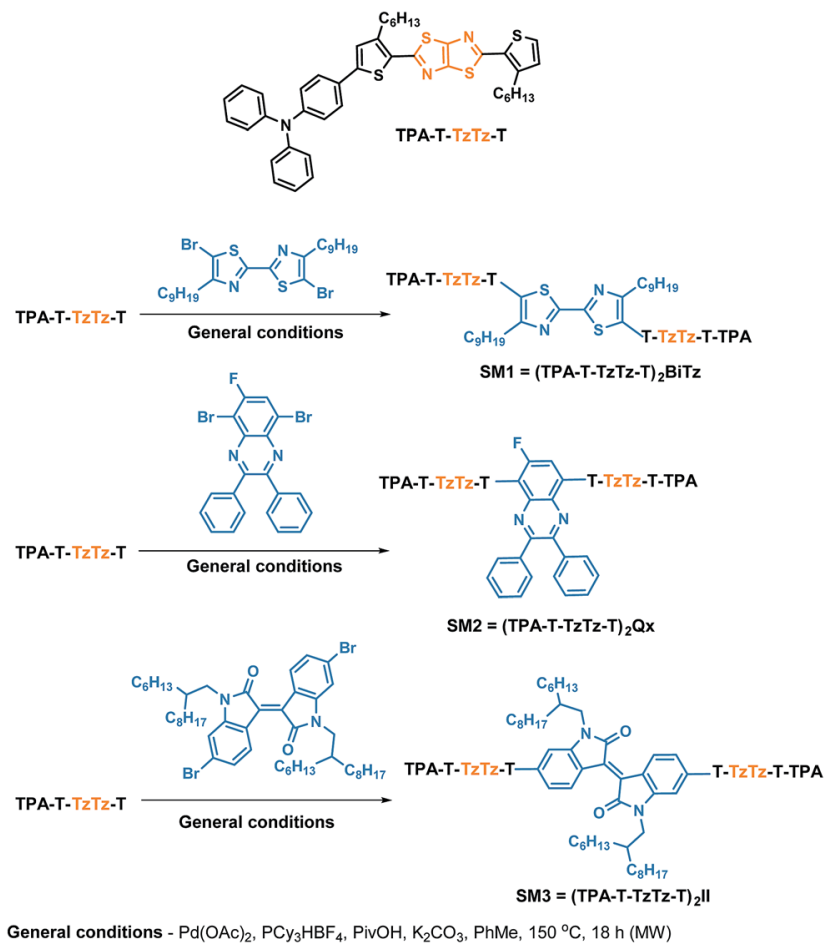

Scheme 1 Combination of the TPA-T-TzTz-T precursor with three different acceptor cores via direct heteroarylation.

by direct (hetero)arylation. Similar $\mathrm{C}-\mathrm{H}$ arylation conditions as previously optimized to construct the monosubstituted TPAT-TzTz-T starting material were employed (Scheme 1), ${ }^{7 d}$ affording the target small molecules SM1-3 in yields of $\sim 30 \%$.

The modest reaction yields can be attributed to the formation of multiple side products. By analysing the filtrate after the final precipitation of SM2 by MALDI-TOF mass spectrometry, homocoupling of the central acceptor unit and branching due the presence of alternative reactive $\mathrm{C}-\mathrm{H}$ groups were identified as the main side reactions (see Fig. S3†). Whereas homocoupling appears in traditional cross-couplings as well and has been shown to have a strong effect on the photovoltaic efficiency, ${ }^{8}$ the observed regioselectivity issues are inherent to C-H arylation procedures. The presence of these side products, also in the case of direct arylation polymerizations, ${ }^{9}$ has often been undervalued, especially with respect to their effect on device performance. Small molecules SM1-3 were carefully purified by standard column chromatography. SM1 and SM3 were additionally purified by recycling preparative size exclusion chromatography (prep-SEC). Due to its limited solubility in chloroform, SM2 was instead precipitated twice in ethyl acetate. Compared to polymers, molecular chromophores are much more versatile probes to evaluate the 'misconnections' in direct arylations. In this respect, MALDI is particularly useful, as impurities hardly observable and not identifiable by NMR clearly showed up in the mass spectra of SM1-3.

UV-vis absorption spectra in solution and thin films were gathered for all three compounds to analyse their light-harvesting capacity (Fig. 1 and S10, $\uparrow$ Table 1). SM3 displayed the broadest absorption spectra, covering almost the entire visible

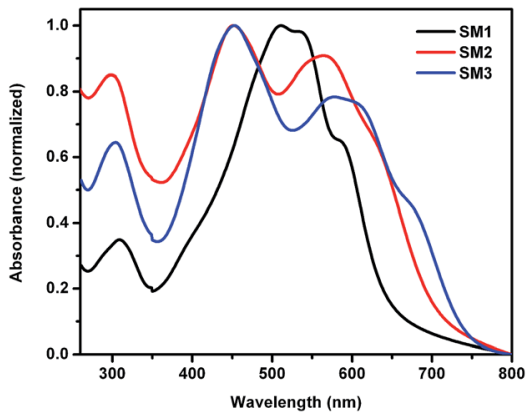

Fig. 1 Normalized UV-vis absorption spectra of the small molecules (in film).

range, and the smallest optical HOMO-LUMO gap. The frontier energy levels were estimated via cyclic voltammetry (CV) from the onset of the oxidation and reduction peaks (Fig. S11, $\dagger$ Table 1). The HOMO levels are nearly invariant (within $0.09 \mathrm{eV}$ ). Since the LUMOs are generally localized on the acceptor parts, a decreasing trend is expected when increasing the electron withdrawing nature of the acceptor building block, which is indeed illustrated in the present series. The narrowest electrochemical HOMO-LUMO gap $(1.45 \mathrm{eV})$ was obtained for the small molecule bearing the strongest acceptor unit (II, SM3), in accordance with the optical data.

The thermal properties of the three small molecules were investigated by rapid heat-cool calorimetry (RHC) (Fig. 2). ${ }^{10}$ The obtained results demonstrate a strong impact on the glass transition temperature $\left(T_{\mathrm{g}}\right)$, melting temperature $\left(T_{\mathrm{m}}\right)$ and melting enthalpy $\left(\Delta H_{\mathrm{m}}\right)$ upon altering the central acceptor unit. SM1 displays two melting temperatures $\left(172 / 244.5^{\circ} \mathrm{C}\right)$, as well as the highest $\Delta H_{\mathrm{m}}\left(30.9 \mathrm{~J} \mathrm{~g}^{-1}\right)$, indicating a highly crystalline character. SM2 appears to be significantly less crystalline $\left(\Delta H_{\mathrm{m}}=4.1 \mathrm{~J} \mathrm{~g}^{-1}\right.$, $\left.T_{\mathrm{m}}=214.1^{\circ} \mathrm{C}\right)$ and a pronounced $T_{\mathrm{g}}\left(112.6^{\circ} \mathrm{C}\right)$ appears. SM3 falls in between, with a $T_{\mathrm{m}}$ of $234.3^{\circ} \mathrm{C}$ and a $\Delta H_{\mathrm{m}}$ of $21.5 \mathrm{~J} \mathrm{~g}^{-1}$.

Thin film BHJ OSCs with the traditional architecture glass/ ITO/PEDOT:PSS/SM1-3:PC ${ }_{71} \mathrm{BM} / \mathrm{Ca} / \mathrm{Al}$ were fabricated to evaluate the photovoltaic features of the synthesized small molecules. Optimal devices were procured from small molecule solutions in chloroform, in combination with $\mathrm{PC}_{71} \mathrm{BM}$ as the electron acceptor in a $1: 1$ (wt/wt\%) ratio (Table 2, Fig. 3, Tables S1-3†). Solar cells produced with SM2 demonstrated the highest photovoltaic performance, yielding an open-circuit voltage $\left(V_{\text {oc }}\right)$ of $0.84 \mathrm{~V}$ in combination with a short-circuit current density $\left(J_{\mathrm{sc}}\right)$ of $9.29 \mathrm{~mA} \mathrm{~cm}{ }^{-2}$ and a fill factor $(\mathrm{FF})$ of 0.55 , resulting in an average PCE of $4.25 \%$ (and a best PCE of $4.86 \%$ ). The performance of SM1 and SM3 was somewhat worse, with average PCEs of 1.77 and $2.11 \%$, respectively. Upon the addition of 1 -chloronaphthalene (CN) as a processing additive, the average PCE of the SM1 device could be enhanced up to $2.50 \%$, mainly attributed to an increased $J_{\mathrm{sc}}$ and $\mathrm{FF}$ (Table 2). Unfortunately, a similar approach did not result in further enhancements for SM2 and SM3. The external quantum efficiency (EQE) spectra reflect the difference in performance for the three small molecule: $\mathrm{PC}_{71} \mathrm{BM}$ OSCs (Fig. S12†) and follow the trend observed in the absorption spectra. The SM2: $\mathrm{PC}_{71} \mathrm{BM}$ device 
Table 1 Optical and electrochemical properties of the small molecule series SM1-3

\begin{tabular}{|c|c|c|c|c|c|c|c|}
\hline & $\lambda_{\max }{ }^{a}(\mathrm{~nm})(\log \varepsilon)$ sol. & $\begin{array}{l}\lambda_{\max } \\
(\mathrm{nm}) \text { film }\end{array}$ & $E_{\mathrm{g}}^{\mathrm{OP} b}(\mathrm{eV})$ & $E_{\mathrm{Ox}}{ }^{c}(\mathrm{~V})$ & HOMO $(\mathrm{eV})$ & $E_{\text {red }}^{c}(\mathrm{~V})$ & LUMO $(\mathrm{eV})$ \\
\hline SM1 & $492(4.70)$ & 507 & 2.17 & 0.47 & -5.33 & -1.59 & -3.26 \\
\hline & $527(4.79)$ & 564 & & & & & \\
\hline SM3 & $\begin{array}{l}449(5.02) \\
598(4.99)\end{array}$ & $\begin{array}{l}452 \\
578\end{array}$ & 1.74 & 0.52 & -5.38 & -0.93 & -3.93 \\
\hline
\end{tabular}

${ }^{a}$ In chloroform. ${ }^{b}$ Optical HOMO-LUMO gaps, determined from the onset of the UV-vis spectra in chloroform. ${ }^{c}$ Oxidation/reduction onsets.

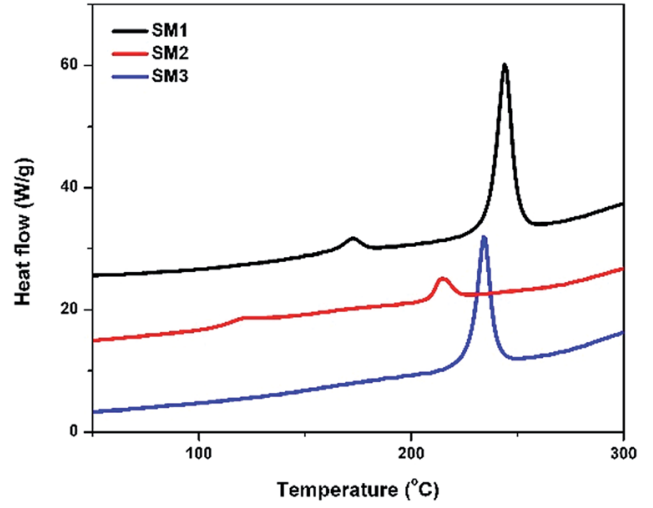

Fig. 2 RHC profiles of SM1-3 (second heating curves, curves shifted vertically for clarity).

Table 2 Photovoltaic output parameters of the (optimized) SM13: $\mathrm{PC}_{71} \mathrm{BM} \mathrm{SMOSCs}^{a}$

\begin{tabular}{|c|c|c|c|c|c|c|}
\hline & Additive $^{b}$ & $V_{\mathrm{oc}}(\mathrm{V})$ & $\begin{array}{l}J_{\mathrm{sc}} \\
\left(\mathrm{mA} \mathrm{cm}{ }^{-2}\right)\end{array}$ & $\mathrm{FF}$ & $\begin{array}{l}\text { Average } \\
\operatorname{PCE}^{c}(\%)\end{array}$ & $\begin{array}{l}\text { Best } \\
\text { PCE (\%) }\end{array}$ \\
\hline SM1 & - & 0.75 & 5.80 & 0.41 & 1.77 & 1.96 \\
\hline SM1 & CN (1\%) & 0.76 & 6.14 & 0.54 & 2.50 & 2.78 \\
\hline SM2 & - & 0.84 & 9.29 & 0.55 & 4.25 & 4.86 \\
\hline SM2 & CN (1\%) & 0.86 & 7.81 & 0.40 & 2.68 & 2.84 \\
\hline $\mathbf{S M} 2^{d}$ & - & 0.84 & 10.18 & 0.57 & 4.91 & 5.09 \\
\hline SM3 & - & 0.86 & 7.04 & 0.35 & 2.11 & 2.42 \\
\hline SM3 & CN (1\%) & 0.85 & 6.41 & 0.32 & 1.73 & 1.83 \\
\hline
\end{tabular}

${ }^{a}$ Device structure: glass/ITO/PEDOT:PSS/SM1-3 : $\mathrm{PC}_{71} \mathrm{BM}(1: 1) / \mathrm{Ca} / \mathrm{Al}$. All active layers were spin-coated from $\mathrm{CHCl}_{3} .{ }^{b} \mathrm{CN}=1$ chloronaphthalene. ${ }^{c}$ Averages taken over $4-8$ devices. ${ }^{d}$ CPE cathodic interlayer (replacing $\mathrm{Ca}$ ).

shows a maximum EQE of $\sim 55 \%$. Noteworthy lower PCEs were obtained when the side products mentioned above were not carefully removed.

The incorporation of interfacial layers, in particular conjugated polyelectrolytes (CPE's), has been documented as a means to boost the inherent $I-V$ properties of BHJ OSCs. ${ }^{11}$ In the previous work, we demonstrated the successful application of a specific ionic copolythiophene (see Fig. S13 $\dagger$ ) as a cathodic interlayer. ${ }^{12}$ Application of this strategy to the SM2 device afforded a further performance improvement, with an average

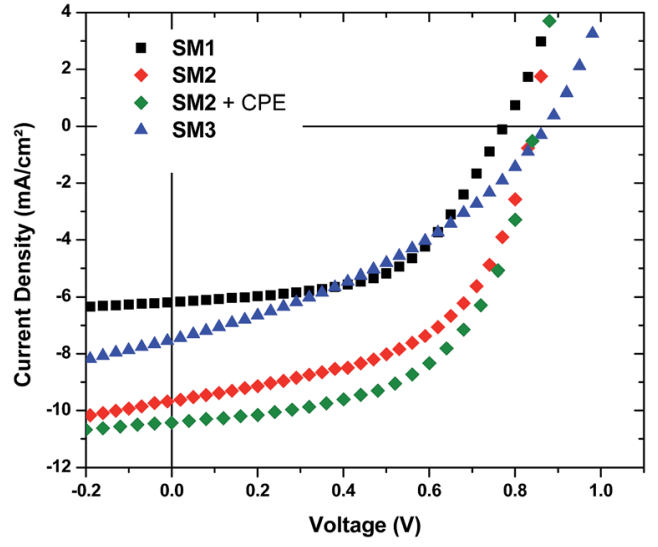

Fig. $3 \mathrm{~J}-V$ curves under illumination of the (average-performance) solar cell devices based on SM1-3 (processed from optimal solvents).

PCE of $4.91 \%$ (best 5.09\%) (Fig. 3, Table 2). The maximum EQE increased up to $\sim 70 \%$ (Fig. S12†).

Mixing of an organic semiconductor with a fullerene gives rise to interfacial charge transfer (CT) states, determining the $V_{\text {oc }}$ of OSCs. ${ }^{13}$ The absorption of the CT state can be directly probed by Fourier transform photocurrent spectroscopy (FTPS). FTPS experiments were done for the SM1-3:PC ${ }_{71} \mathrm{BM}$ solar cells (see Fig. S14 $\dagger$ ) and the observed $E_{\mathrm{CT}}$ values nicely follow the $V_{\mathrm{oc}}$ trend for the prepared devices. Atomic force microscopy (AFM) measurements were performed to investigate the active layer film topographies and to portray the influence of the processing additive. As illustrated in Fig. 4, upon the addition of $\mathrm{CN}$ to the SM1: $\mathrm{PC}_{71} \mathrm{BM}$ blend solution, a significant alteration of the morphology appears, with the formation of specific needleshaped structures, apparently responsible for an increase in $J_{\mathrm{sc}}$ and FF. The addition of the additive to the SM2 solution resulted in a noticeable decrease in the efficiency (the average PCE dropped from 4.25 to $2.68 \%$ ), possibly induced by a nonideal mixing of the donor and acceptor components. The (strong) reduction in $\mathrm{FF}$ and $J_{\mathrm{sc}}$ suggests a decreased charge transport capacity. For SM3, CN did not have a large impact on either the layer topography or solar cell performance.

Finally, field-effect transistors were prepared from the pure chromophores to acquire the mobility data of the small molecule series. The extracted charge carrier mobilities were found to be $\sim 2 \times 10^{-4}, \sim 1 \times 10^{-4}$ and $\sim 6 \times 10^{-5} \mathrm{~cm}^{2} \mathrm{~V}^{-1} \mathrm{~s}^{-1}$ (transfer and output curves in Fig. S15 $\dagger$ ) for SM1, SM2 and SM3, 


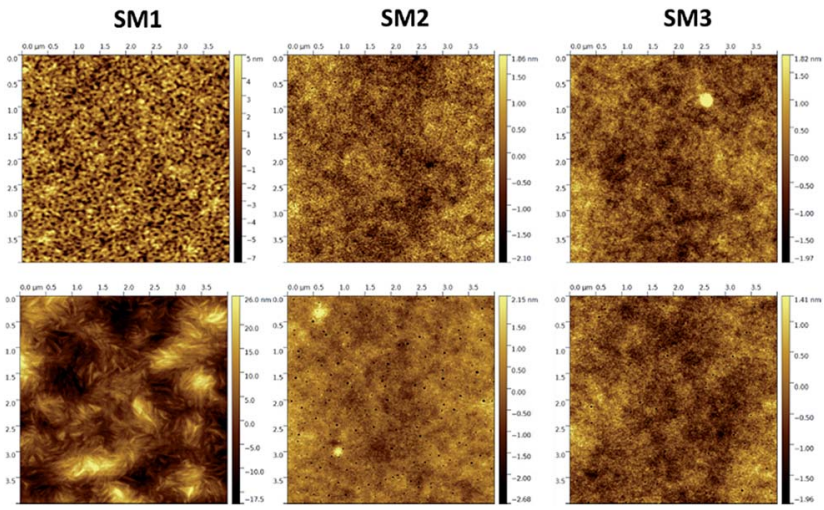

Fig. 4 AFM (topography) images $(4 \times 4 \mu \mathrm{m})$ of the photoactive layers of the SM1-3:PC ${ }_{71} \mathrm{BM}$ solar cells prepared without (upper row) and with (bottom row) $\mathrm{CN}(1 \%)$ as a processing additive.

respectively. The lower charge carrier mobility might partly explain the modest performance of the SMOSCs based on SM3, even though the absorption features are most favourable. For the SM2 and SM3 devices, a similar trend was observed by photo-CELIV (photo-induced charge extraction by linearly increasing voltage; Fig. S16†), probing mobility in the appropriate direction of the solar cell mode.

In conclusion, three $\pi$-expanded $\mathrm{D}^{\prime} \mathrm{A}^{\prime} \mathrm{DADA}^{\prime} \mathrm{D}^{\prime}$-type molecular chromophores were synthesized via a two-fold $\mathrm{C}-\mathrm{H}$ arylation approach and implemented as electron donors in organic solar cells. Their physicochemical and optoelectronic material characteristics were investigated and a PCE of 5.1\% was achieved for the TPA-T-TzTz-T-Qx-T-TzTz-T-TPA small molecule, a record performance of molecular chromophores prepared via direct arylation. ${ }^{7,9}$ Despite the success of the approach, the current limitations of the $\mathrm{C}-\mathrm{H}$ (hetero)arylation protocols should not be ignored. If one desires to employ sustainable direct arylation procedures to reduce the 'synthetic complexity'14 of advanced organic semiconductors, further efforts should be devoted to the optimization of the $\mathrm{C}-\mathrm{H}$ regioselectivity in order to increase reaction yields and simplify compound purification. In this respect, related recent efforts (e.g. catalyst optimization) in the field of direct arylation polymerizations might provide a first entry. ${ }^{9}$

\section{Acknowledgements}

We acknowledge financial support from the Science Policy Office of the Belgian Federal Government (BELSPO; IAP 7/05 project FS2), the Agency for Innovation by Science and Technology in Flanders (IWT; PhD grants J. Brebels and T. Vangerven) and the Research Programme of the Research Foundation - Flanders (FWO; M.ERA-NET project RADESOL and projects G.0415.14N/G.0B67.15N).

\section{Notes and references}

1 (a) Y.-W. Su, S.-C. Lan and K.-H. Wei, Mater. Today, 2012, 15, 554; (b) L. Dou, J. You, Z. Hong, Z. Xu, G. Li, R. A. Street and
Y. Yang, Adv. Mater., 2013, 25, 6642; (c) S. Lizin, S. van Passel, E. de Schepper, W. Maes, L. Lutsen, J. Manca and D. Vanderzande, Energy Environ. Sci., 2013, 6, 3136; (d) K. A. Mazzio and C. K. Luscombe, Chem. Soc. Rev., 2015, 44, 78.

2 B. Kan, M. Li, Q. Zhang, F. Liu, X. Wan, Y. Wang, W. Ni, G. Long, X. Yang, H. Feng, Y. Zuo, M. Zhang, F. Huang, Y. Cao, T. P. Russell and Y. Chen, J. Am. Chem. Soc., 2015, 137, 3886.

3 (a) A. Mishra and P. Bäuerle, Angew. Chem., Int. Ed., 2012, 51, 2020; (b) Y. Lin, Y. Li and X. Zhan, Chem. Soc. Rev., 2012, 41, 4245; (c) J. Roncali, P. Leriche and P. Blanchard, Adv. Mater., 2014, 26, 3821.

4 D. Bevk, L. Lutsen, D. Vanderzande and W. Maes, RSC Adv., 2013, 3, 11418.

5 (a) S. van Mierloo, J. Kesters, A. Hadipour, M.-J. Spijkman, N. van den Brande, J. D'Haen, G. van Assche, D. M. de Leeuw, T. Aernouts, J. Manca, L. Lutsen, D. Vanderzande and W. Maes, Chem. Mater., 2012, 24, 587; (b) I. Osaka, M. Saito, T. Koganezawa and K. Takimiya, Adv. Mater., 2014, 26, 331; (c) S. Subramaniyan, H. Xin, F. Sunjoo Kim, N. M. Murari, B. A. E. Courtright and S. A. Jenekhe, Macromolecules, 2014, 47, 4199; (d) E. Bundgaard, F. Livi, O. Hagemann, J. E. Carlé, M. Helgesen, I. M. Heckler, N. K. Zawacka, D. Angmo, T. T. Larsen-Olsen, G. A. dos Reis Benatto, B. Roth, M. V. Madsen, M. R. Andersson, M. Jørgensen, R. R. Søndergaard and F. C. Krebs, Adv. Energy Mater., 2015, 1402186.

6 (a) Q. Shi, P. Cheng, Y. Li and X. Zhan, Adv. Energy Mater., 2012, 2, 63; (b) P. Dutta, W. Yang, S. H. Eom and S.-H. Lee, Org. Electron., 2012, 13, 273; (c) P. Dutta, H. Park, W.-H. Lee, I.-N. Kang and S.-H. Lee, Org. Electron., 2012, 13, 3183; (d) P. Cheng, Q. Shi, Y. Lin, Y. Li and X. Zhan, Org. Electron., 2013, 14, 599; (e) Y. Chen, Z. Du, W. Chen, S. Wen, L. Sun, Q. Liu, M. Sun and R. Yang, New J. Chem., 2014, 38, 1559.

7 (a) J. Zhang, D.-Y. Kang, S. Barlow and S. R. Marder, J. Mater. Chem., 2012, 22, 21392; (b) S.-Y. Liu, M.-M. Shi, J.-C. Huang, Z.-N. Jin, X.-L. Hu, J.-Y. Pan, H.-Y. Li, A. K. Y. Jen and H.-Z. Chen, J. Mater. Chem. A, 2013, 1, 2795; (c) K. Okamoto, J. Zhang, J. B. Housekeeper, S. R. Marder and C. K. Luscombe, Macromolecules, 2013, 46, 8059; (d) J. Kudrjasova, R. Herckens, H. Penxten, P. Adriaensens, L. Lutsen, D. Vanderzande and W. Maes, Org. Biomol. Chem., 2014, 12, 4663; (e) R. Matsidik, J. Martin, S. Schmidt, J. Obermayer, F. Lombeck, F. Nübling, H. Komber, D. Fazzi and M. Sommer, J. Org. Chem., 2015, 80, 980; (f) S. M. McAfee, J. M. Topple, A.-J. Payne, J.-P. Sun, I. G. Hill and G. C. Welch, ChemPhysChem, 2015, 16, 1190.

8 (a) K. H. Hendriks, W. Li, G. H. L. Heintges, G. W. P. van Pruissen, M. M. Wienk and R. A. J. Janssen, J. Am. Chem. Soc., 2014, 136, 11128; (b) L. Lu, T. Zheng, T. Xu, D. Zhao and L. Yu, Chem. Mater., 2015, 27, 537; (c) T. Vangerven, P. Verstappen, J. Drijkoningen, W. Dierckx, S. Himmelberger, A. Salleo, D. Vanderzande, W. Maes and J. V. Manca, Chem. Mater., 2015, 27, 3726. 
9 (a) P. Berrouard, A. Najari, A. Pron, D. Gendron, P.-O. Morin, J.-R. Pouliot, J. Veilleux and M. Leclerc, Angew. Chem., Int. $E d .$, 2012, 51, 2068; (b) S. Kowalski, S. Allard and U. Scherf, ACS Macro Lett., 2012, 1, 465; (c) E. Iizuka, M. Wakioka and F. Ozawa, Macromolecules, 2015, 48, 2989; (d) R. Matsidik, H. Komber, A. Luzio, M. Caironi and M. Sommer, J. Am. Chem. Soc., 2015, 137, 6705; (e) A. E. Rudenko and B. C. Thompson, J. Polym. Sci., Part A: Polym. Chem., 2015, 53, 135.

10 (a) R. L. Danley, P. A. Caulfield and S. R. Aubuchon, Am. Lab., 2008, 40, 9; (b) T. Ghoos, N. van den Brande, M. Defour, J. Brassinne, C.-A. Fustin, J.-F. Gohy, S. Hoeppener, U. S. Schubert, W. Vanormelingen, L. Lutsen, D. Vanderzande, B. van Mele and W. Maes, Eur. Polym. J., 2014, 53, 206.

11 (a) F. Huang, H. Wu and Y. Cao, Chem. Soc. Rev., 2010, 39, 2500; (b) J. Kesters, T. Ghoos, H. Penxten, J. Drijkoningen,
T. Vangerven, D. M. Lyons, B. Verreet, T. Aernouts, L. Lutsen, D. Vanderzande, J. Manca and W. Maes, Adv. Energy Mater., 2013, 3, 1180; (c) G. Long, X. Wan, B. Kan, Z. Hu, X. Yang, Y. Zhang, M. Zhang, H. Wu, F. Huang, S. Su, Y. Cao and Y. Chen, ChemSusChem, 2014, 7, 2358.

12 (a) T. Ghoos, J. Brassinne, C.-A. Fustin, J.-F. Gohy, M. Defour, N. van Den Brande, B. van Mele, L. Lutsen, D. J. Vanderzande and W. Maes, Polymer, 2013, 54, 6293; (b) W. Vanormelingen, J. Kesters, P. Verstappen, J. Drijkoningen, J. Kudrjasova, S. Koudjina, V. Liégeois, B. Champagne, J. Manca, L. Lutsen, D. Vanderzande and W. Maes, J. Mater. Chem. A, 2014, 2, 7535.

13 K. Vandewal, K. Tvingstedt, A. Gadisa, O. Inganäs and J. V. Manca, Nat. Mater., 2009, 8, 904.

14 R. Po, G. Bianchi, C. Carbonera and A. Pellegrino, Macromolecules, 2015, 48, 453. 